\title{
Efficacy and Safety of Vildagliptin as Add-on to Metformin in Japanese Patients with Type 2 Diabetes Mellitus
}

\author{
Masato Odawara • Izumi Hamada • Manabu Suzuki
}

To view enhanced content go to www.diabetestherapy-open.com

Received: January 23, 2014 / Published online: March 7, 2014

(C) The Author(s) 2014. This article is published with open access at Springerlink.com

\section{ABSTRACT}

Introduction: The objective of this study was to evaluate the efficacy and safety of vildagliptin, a potent dipeptidyl peptidase- 4 inhibitor, as an add-on to metformin in Japanese patients with type 2 diabetes mellitus (T2DM).

Methods: This multicenter, 12-week, randomized, double-blind, placebo-controlled, parallel-arm study compared vildagliptin $50 \mathrm{mg}$ bid with placebo in T2DM patients who were inadequately controlled [glycosylated hemoglobin $\left(\mathrm{HbA}_{1 \mathrm{c}}\right)$ 7.0-10.0\%] on a stable daily dose of metformin monotherapy $(250 \mathrm{mg}$ bid or $500 \mathrm{mg}$ bid).

Trial registration: Clinical Trials.gov \#NCT01497522.

Electronic supplementary material The online version of this article (doi:10.1007/s13300-014-0059-x) contains supplementary material, which is available to authorized users.

M. Odawara ( $\square)$

The Third Department of Internal Medicine,

Tokyo Medical University, Tokyo, Japan

e-mail: odawara@tokyo-med.ac.jp

I. Hamada $\cdot$ M. Suzuki

Novartis Pharma K.K., Tokyo, Japan
Results: A total of 139 patients were randomized to receive either vildagliptin $(n=69) \quad$ or placebo $\quad(n=70)$. Patient demographics were comparable between the groups at baseline. After 12 weeks of treatment, adjusted mean change in $\mathrm{HbA}_{1 \mathrm{c}}$ was $-1.1 \%$ in the vildagliptin group (baseline $8.0 \%$ ) and $-0.1 \%$ in the placebo group (baseline $8.0 \%)$, with a between-treatment difference of $-1.0 \% \quad(P<0.001)$. Vildagliptin showed a similar reduction in $\mathrm{HbA}_{1 \mathrm{c}}$ of $-1.1 \%$ for both the subpopulations of patients receiving metformin $250 \mathrm{mg}$ bid or $500 \mathrm{mg}$ bid $(P<0.001$ vs. baseline). Significantly more patients in the vildagliptin group achieved an $\mathrm{HbA}_{1 \mathrm{c}}$ target of $\leq 6.5 \%(30.9 \%)$ and $<7.0 \%$ $(64.1 \%)$ compared with the placebo group $(P<0.001)$. The between-treatment difference in adjusted mean change in fasting plasma glucose was $-1.6 \mathrm{mmol} / \mathrm{L}(P<0.001)$ in favor of vildagliptin. Patients in the vildagliptin and placebo groups reported comparable incidences of adverse events (44.1\% vs. $41.4 \%$ ). No deaths or hypoglycemic events were reported in the study.

Conclusions: Vildagliptin $50 \mathrm{mg}$ bid added to metformin improved glycemic control without 
any tolerability issues and hypoglycemia in Japanese patients with T2DM inadequately controlled on metformin monotherapy.

Keywords: Antidiabetic drug; Dipeptidyl peptidase-4 inhibitor; Glycemic control; Metformin; Randomized trial; Type 2 diabetes mellitus; Vildagliptin

\section{INTRODUCTION}

In Japan, the estimated number of individuals with type 2 diabetes mellitus (T2DM) is approximately 7.1 million, which is the ninth largest prevalence in the world [1]. In recent years, the prevalence of T2DM in Japan has increased due to lifestyle changes, genetic predisposition, and an aging population [2, 3]. Most of the Japanese T2DM patients are non-obese with an average body mass index (BMI) of $23-25 \mathrm{~kg} / \mathrm{m}^{2}$, impaired insulin secretion plays a key role in the development of T2DM in these patients [4].

Despite major advances in the management of T2DM and availability of a range of antidiabetic agents, evidence suggests that up to $\sim 60 \%$ of patients in Japan [5] fail to achieve the recommended target of glycosylated hemoglobin $\left(\mathrm{HbA}_{1 \mathrm{c}}\right)$ levels $<7.0 \%$ [6].

Metformin is one of the commonly used oral antidiabetic agents (OADs) in Japan. Metformin improves blood glucose levels primarily by inhibiting hepatic glucose production and also improving insulin sensitivity in the liver and skeletal muscles [7]. However, due to the progressive nature of T2DM, long-term glycemic control is difficult to achieve with a single agent, thus often requiring addition of further agents. Addition of a dipeptidyl peptidase-4 (DPP-4) enzyme inhibitor with metformin is beneficial due to their complementary mechanisms of action [8].
Vildagliptin, a potent and selective DPP-4 inhibitor, increases the active levels of incretin hormones, glucagon-like peptide (GLP)-1 and glucose-dependent insulinotropic polypeptide (GIP), thereby improving pancreatic $\alpha$ - and $\beta$ cell sensitivity to glucose [9]. In large-scale clinical trials, vildagliptin improved glycemic control when given as monotherapy [10] or in combination with metformin [11], sulfonylurea [12], thiazolidinedione [13] or insulin [14], with low risk of hypoglycemia and weight gain. Vildagliptin $50 \mathrm{mg}$ bid showed notable improvement in blood glucose levels and better tolerability compared with placebo [15] or voglibose [16] in Japanese patients with T2DM inadequately controlled on diet and exercise. Combination therapy of vildagliptin with lowdose (500 mg bid) and high-dose (1,000 mg bid) metformin showed improved glycemic control compared with individual monotherapies in a large global study [17]. The high dose of metformin ( $>750 \mathrm{mg} /$ day) was approved in Japan in 2010. However, there are limited clinical data on the use of DPP-4 inhibitors in combination with metformin ( $>750 \mathrm{mg} /$ day) in Japanese patients with T2DM. The aim of the present study was to evaluate the efficacy and safety of vildagliptin as add-on therapy in Japanese patients with T2DM inadequately controlled with metformin 500 or $1,000 \mathrm{mg} /$ day. The study was conducted to support registration of the fixed-dose combination of vildagliptin and metformin for the treatment of T2DM in Japan.

\section{MATERIALS AND METHODS}

\section{Study Design}

This was a 12-week, multicenter, randomized, double-blind, parallel-group, placebo-controlled 
study conducted across 20 centers in Japan in patients with T2DM inadequately controlled on metformin and diet/exercise. Following a screening period (visit 1), eligible patients who were on a stable daily dose of metformin $(250 \mathrm{mg}$ bid or $500 \mathrm{mg}$ bid) for at least 10 weeks proceeded directly to randomization (baseline, visit 2) to receive either vildagliptin $50 \mathrm{mg}$ bid or placebo as add-on to metformin in a 1:1 ratio. Patients taking OADs other than metformin were switched to either metformin $250 \mathrm{mg}$ bid or $500 \mathrm{mg}$ bid at the investigator's discretion and were randomized after completing a 12-week run-in period (Fig. 1). This was followed by three scheduled visits from baseline (weeks 4,8 , and 12) during which efficacy and tolerability were assessed. Randomization was stratified to adjust for metformin dose in 1:1 ratio in both the treatment groups. The dose of metformin remained unchanged throughout the study and no rescue medication (additional OADs or insulin) was allowed. Patients with unsatisfactory therapeutic effect [fasting plasma glucose (FPG) $\geq 15.0 \mathrm{mmol} / \mathrm{L}]$ were to be discontinued from the study.

\section{Study Population}

The study enrolled men and women with T2DM, aged $\geq 20$ to $<75$ years, BMI $\geq 20$ to $\leq 35 \mathrm{~kg} / \mathrm{m}^{2}$, baseline $\mathrm{HbA}_{1 \mathrm{c}}$ values $\geq 7.0 \%$ to $\leq 10.0 \%$, who were inadequately controlled on diet, exercise and metformin monotherapy. The patients were required to be on a stable daily dose of metformin $250 \mathrm{mg}$ bid or $500 \mathrm{mg}$ bid for at least 10 weeks prior to randomization.

The key exclusion criteria included history of type 1 diabetes, diabetes due to pancreatic injury or secondary forms, acute metabolic complications such as ketoacidosis or lactic acidosis, liver diseases such as cirrhosis or hepatitis, impaired renal function, congestive heart failure (New York Heart Association Class III or IV), myocardial infarction, stroke or transient ischemic attacks in the past 6 months. Patients with any of the following laboratory abnormalities at baseline were excluded: FPG $\geq 15 \mathrm{mmol} / \mathrm{L}$; alanine transaminase, aspartate transaminase, or total bilirubin $>2$ times the upper limit of normal; and fasting triglycerides $>5.7 \mathrm{mmol} / \mathrm{L}$.

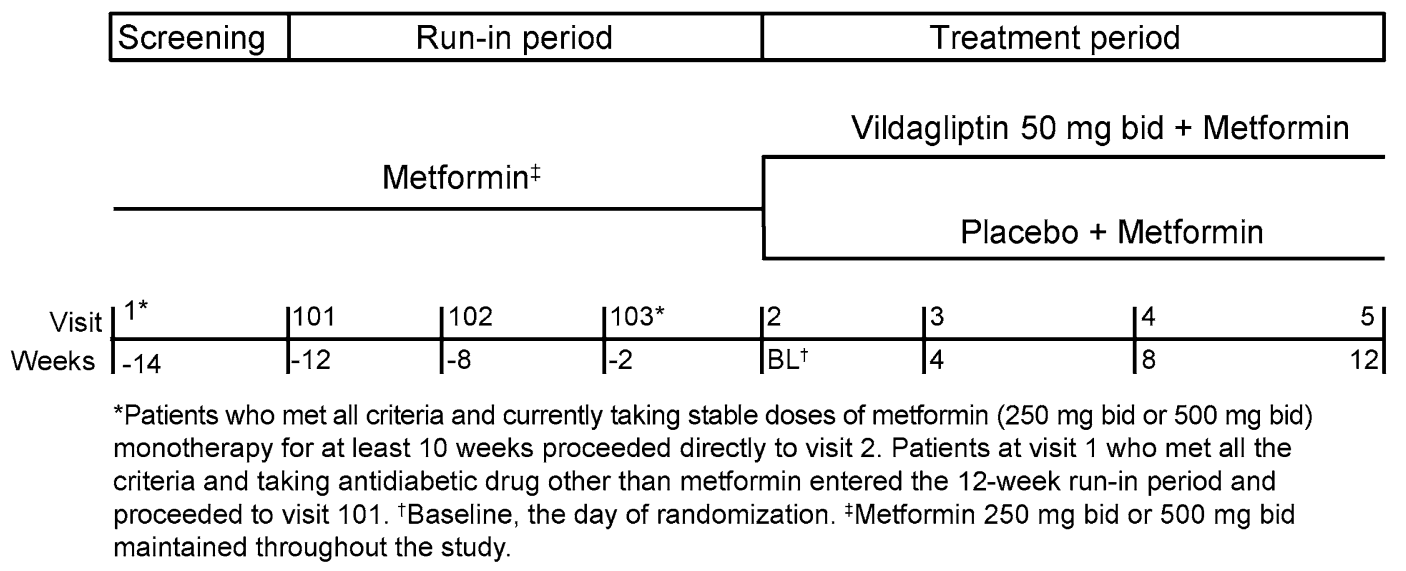

Fig. 1 Study design 


\section{Study Endpoints and Assessments}

The primary efficacy endpoint was the change in $\mathrm{HbA}_{1 \mathrm{c}}$ from baseline to week 12 or the study endpoint. The key secondary efficacy endpoint was change in $\mathrm{HbA}_{1 \mathrm{c}}$ from baseline to study endpoint within subpopulations of patients treated with vildagliptin and metformin (250 mg bid or $500 \mathrm{mg}$ bid). Other secondary efficacy endpoints included percentage of patients (responder rate) achieving predefined $\mathrm{HbA}_{1 \mathrm{c}}$ targets $(\leq 6.5 \%,<7.0 \%$, and reductions of $\geq 0.5 \%$ and $\geq 1.0 \%$ ) and change in FPG levels after 12 weeks of treatment. Changes in $\mathrm{HbA}_{1 \mathrm{c}}$ (reported in National Glycohemoglobin Standardization Program units) and FPG were assessed at each scheduled visit (weeks $0,4,8$, and 12).

Adverse events (AEs) and serious AEs (SAEs) were recorded at each visit, and were assessed for severity, duration, and suspected relationship to the study drug. Standard hematology, biochemistry, liver function tests, urinalysis, vital signs, and body weight were measured at the screening visit and at weeks 0 , 4,8 , and 12. Electrocardiograms were recorded at screening and at the last study visit (week 12). Fasting lipid profile was assessed at baseline and at the last study visit. All the patients were provided with a calibrated home glucose monitor and were instructed regarding its use. The patients were educated regarding hypoglycemic symptoms, possible triggers and were asked to record hypoglycemic event in a study diary. Hypoglycemia was defined as symptoms suggestive of hypoglycemia that was further confirmed by a self-monitored blood glucose measurement of $<3.1 \mathrm{mmol} / \mathrm{L}$. The event was considered grade 1 if the patient was able to initiate self-treatment, and grade 2 if the patient required assistance of another person or hospitalization. All the laboratory assessments were performed at a central laboratory (Mitsubishi Chemical Medience Corporation, Japan).

\section{Statistical Analysis}

A total of 136 patients (68 patients per group) were to be randomized (1:1) to achieve a target sample size of 128 patients (64 per group), assuming a dropout rate of $5 \%$. This sample size would ensure at least $92 \%$ power to detect a clinically relevant between-group difference of $0.6 \%$ absolute units in $\mathrm{HbA}_{1 \mathrm{c}}$ change from baseline, assuming a one-sided significance level of 0.025 , to demonstrate the superiority of vildagliptin $50 \mathrm{mg}$ bid over placebo as add-on to metformin in reducing $\mathrm{HbA}_{1 \mathrm{c}}$ after 12 weeks of treatment. Moreover, randomization was stratified by metformin dose to ensure that patients on metformin $250 \mathrm{mg}$ bid and $500 \mathrm{mg}$ bid each constituted $\sim 50 \%$ of the randomized population. The planned sample size of 136 patients (34 patients in each metformin subpopulation in the vildagliptin group) would provide at least $90 \%$ power to detect a statistically significant reduction in $\mathrm{HbA}_{1 \mathrm{c}}$ of $0.6 \%$ from baseline in each metformin subgroup (250 mg bid or $500 \mathrm{mg}$ bid), assuming a one-sided significance level of 0.025 .

The primary and secondary efficacy analyses were based on the full analysis set, which included all randomized patients who received at least one dose of the study drug and had at least one post-randomization efficacy parameter assessment. Changes in $\mathrm{HbA}_{1 \mathrm{c}}$ and FPG from baseline to study endpoint were analyzed using the analysis of covariance model (ANCOVA), with treatment groups and metformin dose as classification variables and baseline $\mathrm{HbA}_{1 \mathrm{c}}$ as covariate. The study endpoint is the final available post-randomization assessment value 
at any visit (scheduled or unscheduled) up to final visit (week 12). The between-treatment difference in $\mathrm{HbA}_{1 \mathrm{c}}$ and FPG was also analyzed using ANCOVA. Change in $\mathrm{HbA}_{1 \mathrm{c}}$ from baseline to study endpoint within the metformin subpopulations was analyzed using a paired $t$ test. Missing data because of early discontinuation were handled using the last observation carried forward method. The impact of various baseline characteristics (age, gender, $\mathrm{BMI}, \mathrm{HbA}_{1 \mathrm{c}}$, and $\mathrm{FPG}$ ) on absolute change in $\mathrm{HbA}_{1 \mathrm{c}}$ from baseline to endpoint was analyzed using descriptive statistics. The proportion of responders $\left(\mathrm{HbA}_{1 \mathrm{c}} \leq 6.5 \%\right.$ at endpoint, $\mathrm{HbA}_{1 \mathrm{c}}<7 \%$ at endpoint, and reductions in $\mathrm{HbA}_{1 \mathrm{c}} \geq 0.5 \%$ and $\geq 1 \%$ ) in each treatment group was computed and compared using the Chi-square test. The data analysis for this study was carried out using SAS software (version 9.2, SAS Institute Inc., Cary, NC, USA). The safety set consisted of all patients who received at least one dose of the study drug. Safety data were summarized descriptively by treatment. The incidences of treatmentemergent AEs were summarized by system organ class (SOC), preferred term (PT), severity, and relationship to the study drug. AEs were coded by primary SOC and PT according to Medical Dictionary for Drug Regulatory Activities (MedDRA version 15.1).

\section{Ethics and Good Clinical Practice}

The study protocol was reviewed and approved by the Independent Ethics Committee/ Institutional Review Board at each center. All procedures followed were in accordance with the ethical standards of the responsible committee on human experimentation (institutional and national), the Helsinki Declaration of 1975, as revised in 2000 and 2008 and Good Clinical Practice guidelines.
Informed consent was obtained from all patients for being included in the study. The study is registered with ClinicalTrials.gov, identifier: NCT01497522.

\section{RESULTS}

\section{Patient Disposition and Baseline Characteristics}

Of the 139 randomized patients (vildagliptin, $n=69$; placebo, $n=70), 133$ patients $(95.7 \%)$ completed the study (Fig. 2). The primary reasons for discontinuation in the study were AEs (3 patients) and protocol deviations (2 patients) (Fig. 2). Patient demographics and baseline characteristics were comparable between the treatment groups (Table 1). Overall mean age, BMI, baseline $\mathrm{HbA}_{1 \mathrm{c}}$, baseline FPG, and duration of T2DM were 58.1 years, $25.6 \mathrm{~kg} / \mathrm{m}^{2}, 8.0 \%, 9.2 \mathrm{mmol} / \mathrm{L}$, and 7.1 years, respectively. The patients were predominantly men (66.2\%), and more patients were aged $\geq 65$ years in the

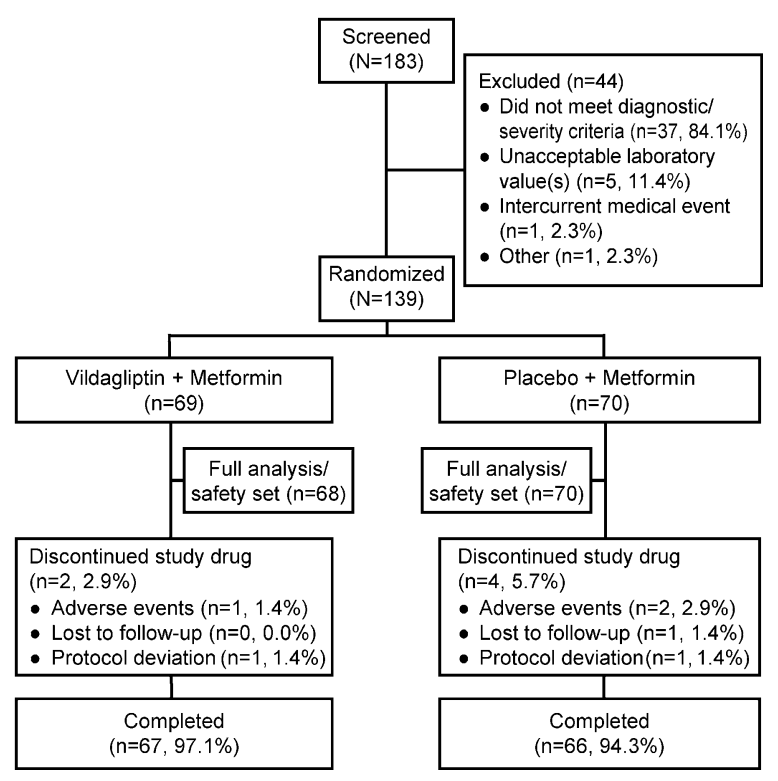

Fig. 2 Patient disposition 
Table 1 Patient demographics and baseline characteristics (randomized set)

\begin{tabular}{|c|c|c|c|}
\hline Parameter & $\begin{array}{l}\text { Vildagliptin } \\
+ \text { metformin } \\
n=69\end{array}$ & $\begin{array}{l}\text { Placebo } \\
+ \text { metformin } \\
n=70\end{array}$ & Total $N=139$ \\
\hline Age, years & $58.7(9.81)$ & $57.5(9.15)$ & $58.1(9.47)$ \\
\hline$\geq 65$ years, $n(\%)$ & $22(31.9)$ & $16(22.9)$ & $38(27.3)$ \\
\hline Men, $n(\%)$ & $44(63.8)$ & $48(68.6)$ & $92(66.2)$ \\
\hline Body weight, $\mathrm{kg}$ & $67.9(12.70)$ & $70.0(13.02)$ & $68.9(12.85)$ \\
\hline BMI, $\mathrm{kg} / \mathrm{m}^{2}$ & $25.3(3.56)$ & $25.9(4.01)$ & $25.6(3.79)$ \\
\hline $\mathrm{HbA}_{1 \mathrm{c}}, \%$ & $8.0(0.83)$ & $8.0(0.96)$ & $8.0(0.90)$ \\
\hline$\leq 8 \%, n(\%)$ & $40(58.0)$ & $40(57.1)$ & $80(57.6)$ \\
\hline$>8$ to $\leq 9 \%, n(\%)$ & $17(24.6)$ & $14(20.0)$ & $31(22.3)$ \\
\hline$>9 \%, n(\%)$ & $12(17.4)$ & $16(22.9)$ & $28(20.1)$ \\
\hline $\mathrm{FPG}, \mathrm{mmol} / \mathrm{L}$ & $9.1(1.80)$ & $9.3(2.40)$ & $9.2(2.12)$ \\
\hline$\geq 8.9 \mathrm{mmol} / \mathrm{L}, n(\%)$ & $28(40.6)$ & $36(51.4)$ & $64(46.0)$ \\
\hline Duration of T2DM, years & $7.2(6.18)$ & $7.0(5.92)$ & $7.1(6.03)$ \\
\hline Metformin total daily dose, $\mathrm{mg}$ & $753.6(251.81)$ & $750.0(251.81)$ & $751.8(250.90)$ \\
\hline Metformin $\leq 500 \mathrm{mg} /$ day, $n(\%)$ & $34(49.3)$ & $35(50.0)$ & $69(49.6)$ \\
\hline Metformin $>500 \mathrm{mg} /$ day, $n(\%)$ & $35(50.7)$ & $35(50.0)$ & $70(50.4)$ \\
\hline \multicolumn{4}{|c|}{ eGFR (MDRD), $\mathrm{mL} / \mathrm{min} / 1.73 \mathrm{~m}^{2}, n(\%)$} \\
\hline Normal, $>80$ & $66(95.7)$ & $64(91.4)$ & $130(93.5)$ \\
\hline Mild, $\geq 50$ to $\leq 80$ & $3(4.3)$ & $6(8.6)$ & $9(6.5)$ \\
\hline Moderate, $\geq 30$ to $<50$ & $0(0.0)$ & $0(0.0)$ & $0(0.0)$ \\
\hline
\end{tabular}

Values are expressed as mean (standard deviation) unless specified otherwise $B M I$ body mass index, eGFR estimated glomerular filtration rate, $F P G$ fasting plasma glucose, $H b A_{1 c}$ glycosylated hemoglobin, $M D R D$ modification of diet in renal disease, $O A D s$ oral antidiabetic drugs, T2DM type 2 diabetes mellitus

vildagliptin group $(31.9 \%)$ than in the placebo group (22.9\%).

\section{Efficacy}

The mean change in $\mathrm{HbA}_{1 \mathrm{c}}$ during the 12 weeks of treatment was consistently lower with vildagliptin than with placebo (Fig. 3a). The overall adjusted mean change $(\mathrm{AM} \Delta) \pm \mathrm{SE}$ in $\mathrm{HbA}_{1 \mathrm{c}}$ was $-1.1 \pm 0.06 \%$ in the vildagliptin group (baseline $8.0 \%$ ) and $-0.1 \pm 0.06 \%$ in the placebo group (baseline 8.0\%), with a statistically significant between-treatment difference of $-1.0 \pm 0.09 \% \quad(P<0.001)$ in favor of vildagliptin (Fig. 3b). Vildagliptin also showed statistically significant reductions from baseline in $\mathrm{HbA}_{1 \mathrm{c}}$ for subpopulations of patients receiving metformin $250 \mathrm{mg}$ bid and $500 \mathrm{mg}$ bid (Table 2). Significantly more patients with vildagliptin achieved $\mathrm{HbA}_{1 \mathrm{c}}$ targets of $\leq 6.5 \%(30.9 \%)$ and $<7.0 \%(64.1 \%)$ compared with placebo $(P<0.001)$. A higher 
proportion of patients in the vildagliptin group achieved $\mathrm{HbA}_{1 \mathrm{c}}$ reductions of $\geq 1 \%$ and $\geq 0.5 \%$ than in the placebo group $(P<0.001)$ (Table 3).

The mean changes in $\mathrm{HbA}_{1 \mathrm{c}}$ from baseline to endpoint in the subgroups of patients by age, gender, baseline $\mathrm{BMI}$, baseline $\mathrm{HbA}_{1 \mathrm{c}}$ and baseline FPG are presented in Table 4. The mean changes in $\mathrm{HbA}_{1 \mathrm{c}}$ were greater for vildagliptin compared with placebo across all the subgroups. Mean reductions in $\mathrm{HbA}_{1 \mathrm{c}}$ in the vildagliptin group were higher in the subgroups of patients with higher baseline $\mathrm{HbA}_{1 \mathrm{c}}\left(\mathrm{HbA}_{1 \mathrm{c}}\right.$ $>8 \%$ to $\leq 9 \%$ or $>9 \%)$ or $\mathrm{FPG}(\geq 8.9 \mathrm{mmol} / \mathrm{L})$ and in those with lower baseline BMI $\left(<25 \mathrm{~kg} / \mathrm{m}^{2}\right)$.
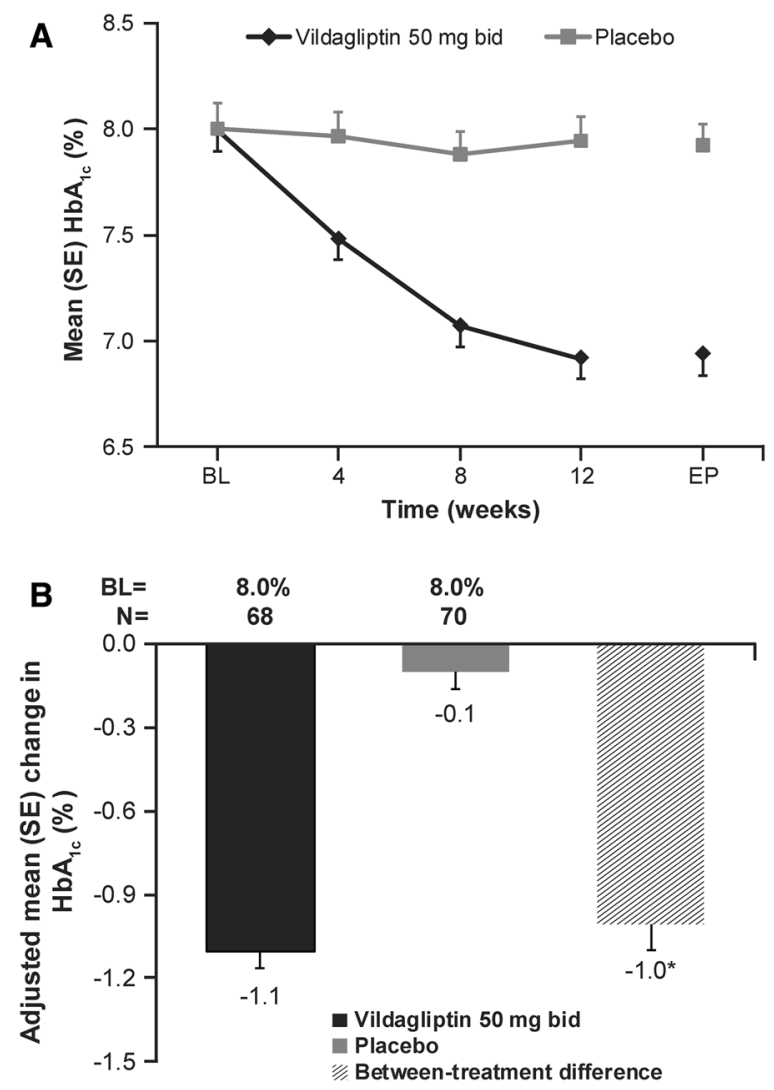

Fig. 3 a Mean glycosylated hemoglobin $\left(\mathrm{HbA}_{1 \mathrm{c}}\right)$ by treatment and visit (full analysis set). b Adjusted mean change in $\mathrm{HbA}_{1 \mathrm{c}}$ from baseline to endpoint (full analysis set). $B L$ baseline, $E P$ endpoint, $S E$ standard error. ${ }^{*} P<0.001$
Vildagliptin showed sustained reduction in FPG over placebo during the 12 weeks of treatment (Fig. 4a). The AM $\Delta \pm \mathrm{SE}$ in FPG from baseline to endpoint was greater in patients receiving vildagliptin $(-1.7 \pm 0.16 \mathrm{mmol} / \mathrm{L})$ compared with those receiving placebo $(-0.1 \pm 0.16 \mathrm{mmol} / \mathrm{L})$, with a between-treatment difference of $-1.6 \pm 0.22 \mathrm{mmol} / \mathrm{L} \quad(P<0.001)$ (Fig. 4b).

\section{Safety}

The overall proportion of patients experiencing AEs was comparable between the vildagliptin (44.1\%) and placebo (41.4\%) groups. The most commonly reported AE by primary SOC was "infections and infestations" $(13.2 \%$ for vildagliptin and $14.3 \%$ for placebo). The most frequently reported $\mathrm{AE}$ ( $\geq 2 \%$ in any group) by PT was "nasopharyngitis" (7.4\% for vildagliptin and $5.7 \%$ for placebo) (Table 5). While incidence of AEs was low across PTs in both the treatment groups, "amylase increased" was reported in more patients with vildagliptin (4 patients; $5.9 \%$ ) than with placebo (1 patient; $1.4 \%)$ and anemia was more frequent with placebo (3 patients; 4.3\%) than with vildagliptin ( 0 patient). All the events of increased amylase levels were classified as mild and clinically asymptomatic. All the reported AEs were mild or moderate in severity. The incidence of AEs suspected to be related to the study drug was slightly higher in the vildagliptin group than in the placebo group $(16.2 \%$ vs. $10.0 \%)$. One patient in the vildagliptin group and two patients in the placebo group discontinued the study. No SAEs were reported in the vildagliptin group, whereas one SAE of myocardial infarction was reported in the placebo group. There were no deaths during the study. No hypoglycemic events were reported in the study. There was 
Table 2 Change in $\mathrm{HbA}_{1 \mathrm{c}}$ (\%) in subpopulations of patients taking metformin $250 \mathrm{mg}$ bid or $500 \mathrm{mg}$ bid (full analysis set)

\begin{tabular}{lllll}
\hline Treatment & $\boldsymbol{n}$ & Baseline mean $(\mathrm{SE})$ & Mean change $(\mathrm{SE})$ & $\mathbf{9 5 \%}$ CI $(\boldsymbol{P}$ value $)$ \\
\hline Vildagliptin + metformin $250 \mathrm{mg}$ bid & 34 & $7.9(0.13)$ & $-1.1(0.09)$ & $-1.24,-0.88(P<0.001)$ \\
Vildagliptin + metformin $500 \mathrm{mg}$ bid & 34 & $8.1(0.15)$ & $-1.1(0.09)$ & $-1.24,-0.88(P<0.001)$ \\
\hline
\end{tabular}

$C I$ confidence interval, $H b A_{l c}$ glycosylated hemoglobin, $S E$ standard error

Table $3 \mathrm{HbA}_{1 \mathrm{c}}$ responder rates (full analysis set)

\begin{tabular}{lll}
\hline Responder criteria & Vildagliptin + metformin $\boldsymbol{n}=\mathbf{6 8}$ & Placebo + metformin $\boldsymbol{n}=\mathbf{7 0}$ \\
\hline $\mathrm{HbA}_{1 \mathrm{c}} \leq 6.5 \%, n / N^{\mathrm{a}}(\%)$ & $21 / 68(30.9)^{*}$ & $2 / 70(2.9)$ \\
$\mathrm{HbA}_{1 \mathrm{c}}<7.0 \%, n / N^{\mathrm{b}}(\%)$ & $41 / 64(64.1)^{*}$ & $9 / 59(15.3)$ \\
Reduction of $\mathrm{HbA}_{1 \mathrm{c}} \geq 1 \%, n / N^{\mathrm{c}}(\%)$ & $39 / 68(57.4)^{*}$ & $3 / 70(4.3)$ \\
Reduction of $\mathrm{HbA}_{1 \mathrm{c}} \geq 0.5 \%, n / N^{\mathrm{c}}(\%)$ & $59 / 68(86.8)^{*}$ & $13 / 70(18.6)$ \\
\hline
\end{tabular}

$H b A_{1 c}$ glycosylated hemoglobin

${ }^{*} P<0.001$

${ }^{a}$ Denominator includes patients with a baseline of $\mathrm{HbA}_{1 \mathrm{c}}>6.5 \%$ and endpoint $\mathrm{HbA}_{1 \mathrm{c}}$ measurement

b Denominator includes patients with a baseline of $\mathrm{HbA}_{1 \mathrm{c}} \geq 7 \%$ and endpoint $\mathrm{HbA}_{1 \mathrm{c}}$ measurement

${ }^{c}$ Denominator includes patients with both baseline and endpoint $\mathrm{HbA}_{1 \mathrm{c}}$ measurements

no change in body weight from baseline to endpoint for both treatment groups $(+0.3 \mathrm{~kg}$ for vildagliptin and $-0.2 \mathrm{~kg}$ for placebo). There were no clinically relevant changes or trends in the hematological, biochemical (including lipid parameters), hepatic enzyme, urinalysis parameters, and vital signs in either treatment group.

\section{DISCUSSION}

This 12-week, randomized, double-blind study evaluated the efficacy and safety of vildagliptin $50 \mathrm{mg}$ bid in Japanese patients with T2DM inadequately controlled on metformin monotherapy. Vildagliptin produced a statistically significant and clinically meaningful change in $\mathrm{HbA}_{1 \mathrm{c}}$ compared with placebo $(-1.1 \%$ vs. $-0.1 \% ; P<0.001)$ as add-on to metformin ( $250 \mathrm{mg}$ bid or $500 \mathrm{mg}$ bid) after 12 weeks of treatment in Japanese patients with T2DM. Despite the lower baseline mean $\mathrm{HbA}_{1 \mathrm{c}}$ and daily dose of metformin in this study, the between-treatment difference $(-1.0 \%)$ seen was consistent with the findings previously reported in a predominantly Caucasian population, where vildagliptin-treated patients showed a decrease in $\mathrm{HbA}_{1 \mathrm{c}}$ of $1.1 \%$ vs. placebo over 24 weeks of treatment [11]. Moreover, the reduction in $\mathrm{HbA}_{1 \mathrm{c}}$ levels reported with vildagliptin therapy was consistent with other DPP-4 inhibitors with different study designs in Japanese population [18-20]. These findings indicate that vildagliptin is effective in Japanese patients with T2DM when added to metformin monotherapy.

Further, vildagliptin showed statistically significant and clinically meaningful reduction 
Table 4 Mean changes in $\mathrm{HbA}_{1 \mathrm{c}}$ (\%) from baseline to endpoint by subgroups (full analysis set)

\begin{tabular}{|c|c|c|c|c|c|c|}
\hline \multirow[t]{2}{*}{ Subgroups } & \multicolumn{3}{|c|}{ Vildagliptin + metformin $n=68$} & \multicolumn{3}{|c|}{ Placebo + metformin $n=70$} \\
\hline & $\bar{n}$ & $B L$ mean & Change (SE) & $\bar{N}$ & $B L$ mean & Change (SE) \\
\hline \multicolumn{7}{|l|}{ Age (years) } \\
\hline$<65$ & 47 & 7.9 & $-1.1(0.08)$ & 54 & 8.0 & $-0.1(0.08)$ \\
\hline$\geq 65$ & 21 & 8.3 & $-1.1(0.15)$ & 16 & 7.9 & $-0.2(0.08)$ \\
\hline \multicolumn{7}{|l|}{ Gender } \\
\hline Male & 44 & 7.9 & $-1.0(0.10)$ & 48 & 8.1 & $-0.2(0.07)$ \\
\hline Female & 24 & 8.2 & $-1.2(0.09)$ & 22 & 7.9 & $-0.1(0.13)$ \\
\hline \multicolumn{7}{|c|}{ BMI $\left(\mathrm{kg} / \mathrm{m}^{2}\right)$} \\
\hline$<25$ & 32 & 8.0 & $-1.2(0.11)$ & 35 & 7.8 & $-0.2(0.08)$ \\
\hline$\geq 25$ & 36 & 8.0 & $-0.9(0.08)$ & 35 & 8.2 & $0.0(0.10)$ \\
\hline \multicolumn{7}{|l|}{$\mathrm{HbA}_{1 \mathrm{c}}(\%)$} \\
\hline$\leq 8$ & 40 & 7.4 & $-0.9(0.07)$ & 40 & 7.3 & $0.0(0.08)$ \\
\hline$>8$ to $\leq 9$ & 17 & 8.3 & $-1.1(0.14)$ & 14 & 8.5 & $0.0(0.10)$ \\
\hline$>9$ & 11 & 9.5 & $-1.6(0.26)$ & 16 & 9.4 & $-0.3(0.17)$ \\
\hline \multicolumn{7}{|c|}{$\mathrm{FPG}(\mathrm{mmol} / \mathrm{L})$} \\
\hline$<8.9$ & 41 & 7.6 & $-1.0(0.08)$ & 34 & 7.3 & $-0.1(0.06)$ \\
\hline$\geq 8.9$ & 27 & 8.6 & $-1.2(0.14)$ & 36 & 8.7 & $-0.1(0.11)$ \\
\hline
\end{tabular}

$B L$ baseline, $B M I$ body mass index, $F P G$ fasting plasma glucose, $H b A_{1 c}$ glycosylated hemoglobin, $S E$ standard error

in $\mathrm{HbA}_{1 \mathrm{c}}$ after 12 weeks of treatment in the subpopulation of patients receiving metformin $250 \mathrm{mg}$ bid or $500 \mathrm{mg}$ bid. Treatment with vildagliptin produced greater reduction in $\mathrm{HbA}_{1 \mathrm{c}}$ compared with placebo regardless of age, gender, baseline $\mathrm{BMI}, \mathrm{HbA}_{1 \mathrm{c}}$ and FPG. Vildagliptin was efficacious irrespective of the baseline $\mathrm{HbA}_{1 \mathrm{c}}$. Greater reduction was seen in patients with higher baseline, which is consistent with the results observed in a predominantly Caucasian population [11].

Approximately one-third of patients treated with vildagliptin (30.9\%) achieved the predefined $\mathrm{HbA}_{1 \mathrm{c}}$ target of $\leq 6.5 \%$. Furthermore, almost two-thirds of patients $(64.1 \%)$ reached the $\mathrm{HbA}_{1 \mathrm{c}}$ target of $<7.0 \%$, a goal recommended by the Japanese Diabetes Society [6]. The responder rate $(<7.0 \%)$ was higher than that reported in a predominantly Caucasian population (55.4\%) [11]. Over half of the population $(57.4 \%)$ achieved an $\mathrm{HbA}_{1 \mathrm{c}}$ reduction of $\geq 1.0 \%$, and $86.8 \%$ of patients reported a reduction of $\geq 0.5 \%$ in the vildagliptin group.

Vildagliptin showed statistically significant reduction in FPG levels vs. placebo $(P<0.001)$ as add-on to metformin monotherapy after 12 weeks of treatment. The decrease in FPG could be attributed to increased active levels of GLP-1 upon twice-daily administration of vildagliptin $50 \mathrm{mg}$, which enhances insulin secretion and suppresses glucagon levels 

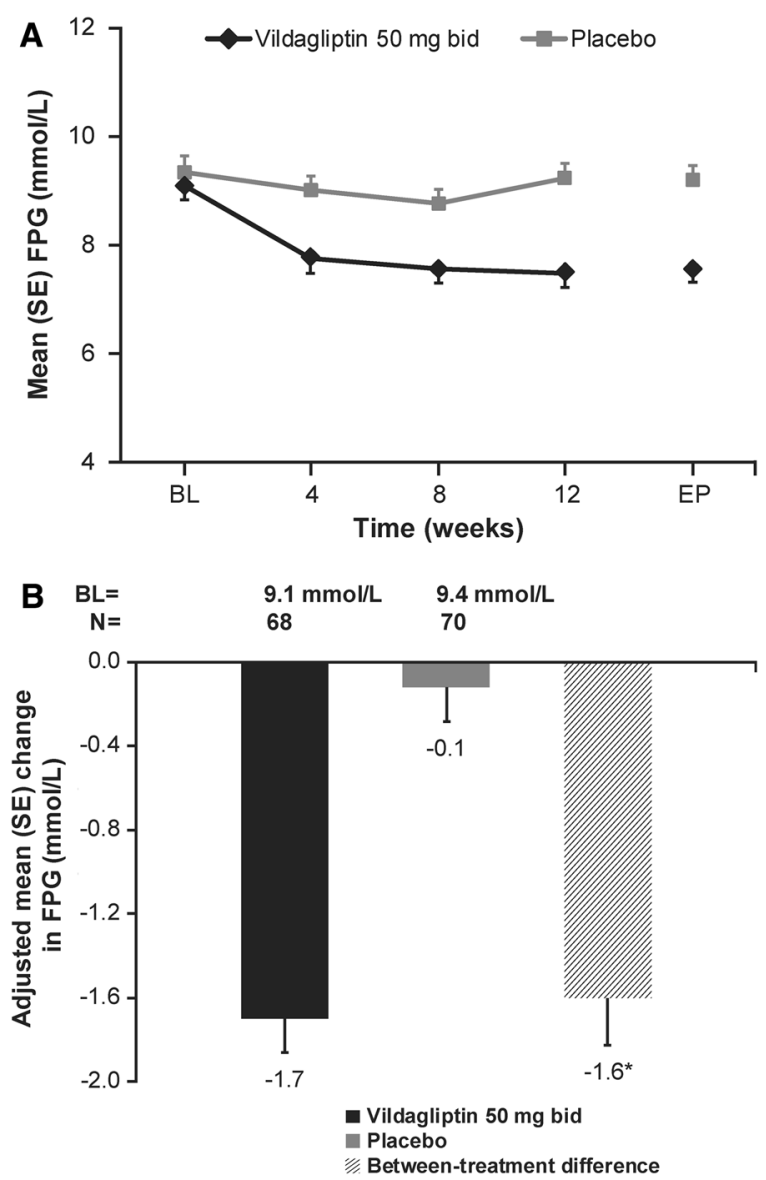

Fig. 4 a Fasting plasma glucose (FPG) by treatment and visit (full analysis set). b Adjusted mean change in FPG from baseline to endpoint (full analysis set). $B L$ baseline, $E P$ endpoint, $S E$ standard error. ${ }^{*} P<0.001$

relative to glucose levels, in turn decreasing the endogenous glucose production overnight [21].

Overall, vildagliptin added to metformin was safe with no new safety findings observed in Japanese patients with T2DM. The observed safety profile was similar with previously reported 52-week safety study of vildagliptin add-on to metformin in Japanese patients with T2DM [22], long-term study of vildagliptin add-on to metformin in a predominantly Caucasian population [23], and safety pooled analysis of vildagliptin studies of $\geq 12$ to $\geq 104$ weeks duration [24]. Four patients in the vildagliptin

Table 5 Number (\%) of patients reporting common adverse events $(\geq 2 \%$ in any group) by preferred term (safety set)

\begin{tabular}{lll}
\hline $\begin{array}{l}\text { Preferred } \\
\text { term, } \boldsymbol{n}(\%)\end{array}$ & $\begin{array}{l}\text { Vildagliptin } \\
\text { + metformin } \\
\boldsymbol{n}=\mathbf{6 8}\end{array}$ & $\begin{array}{l}\text { Placebo } \\
\text { + metformin } \\
\boldsymbol{n}=\mathbf{7 0}\end{array}$ \\
\hline Any preferred term & $30(44.1)$ & $29(41.4)$ \\
Nasopharyngitis & $5(7.4)$ & $4(5.7)$ \\
Amylase increased & $4(5.9)$ & $1(1.4)$ \\
Dental caries & $2(2.9)$ & $0(0.0)$ \\
Gastritis erosive & $2(2.9)$ & $0(0.0)$ \\
Tinea infection & $2(2.9)$ & $0(0.0)$ \\
Lipase increased & $2(2.9)$ & $1(1.4)$ \\
Hypoesthesia & $2(2.9)$ & $0(0.0)$ \\
Anemia & $0(0.0)$ & $3(4.3)$ \\
Diarrhea & $0(0.0)$ & $2(2.9)$ \\
Gastroenteritis & $0(0.0)$ & $2(2.9)$ \\
Alanine & $0(0.0)$ & $2(2.9)$ \\
aminotransferase & & \\
increased & & $2(2.9)$ \\
Aspartate & $0(0.0)$ & \\
aminotransferase & & \\
increased & & $2(2.9)$ \\
Back pain & $0(0.0)$ & \\
Headache & $0(0.0)$ & \\
Tension headache & $0(0.0)$ & \\
\hline
\end{tabular}

group and one patient in the placebo group reported clinically asymptomatic mild elevations of amylase and/or lipase; however, none of these cases were considered as an AE of acute pancreatitis by the investigators. Similar to the previously reported studies [25], treatment with vildagliptin as add-on to metformin confirmed its weight neutrality in Japanese patients.

There were no incidences of hypoglycemia reported in the study. Absence of hypoglycemic events in the vildagliptin group, in spite of lower mean baseline FPG and $\mathrm{HbA}_{1 \mathrm{c}}$ levels than the 
global study [11], confirms the glucose-dependent action of vildagliptin. This is consistent with the results from a previously reported large pooled analysis of global safety data, which showed that vildagliptin, as monotherapy or in combination with metformin, thiazolidinedione, or sulfonylurea, is associated with fewer hypoglycemic events compared with comparators [24].

The notable benefit observed in improving $\mathrm{HbA}_{1 \mathrm{c}}$ levels confirms the complementary mechanism of action of vildagliptin and metformin in Japanese patients with T2DM. Metformin increases the plasma concentration of incretin hormones and enhances the effects of DPP-4 inhibition on the increase of intact GLP-1, which might explain the improved efficacy of vildagliptin in combination with metformin [26].

In conclusion, vildagliptin $50 \mathrm{mg}$ bid as addon to metformin is effective in reducing $\mathrm{HbA}_{1 \mathrm{c}}$ and FPG levels without any tolerability issues and hypoglycemia in Japanese patients with T2DM inadequately controlled on metformin monotherapy.

\section{ACKNOWLEDGMENTS}

The authors would like to thank the patients and staff who participated in this study. Sponsorship and article processing charges for this study were funded by Novartis Pharma K.K. The authors take full responsibility for the content of the manuscript and participated at all stages of manuscript development and approved the final manuscript for publication. Masato Odawara and Manabu Suzuki contributed to study design, data analysis and interpretation and contributed to drafting of the manuscript. Izumi Hamada provided support for statistical analysis. All authors meet the ICMJE criteria for authorship, had full access to the study data and take complete responsibility for the integrity of the data and accuracy of the data analysis. Medical writing assistance, editorial assistance, and collation and incorporation of comments from all authors for this study were provided by Anuja Shah (Novartis Healthcare Pvt. Ltd., Hyderabad, India) and Amit Garg (Novartis Healthcare Pvt. Ltd., Hyderabad, India).

Conflict of interest. Manabu Suzuki is an employee of Novartis Pharma K.K. Izumi Hamada is an employee of Novartis Pharma K.K. Masato Odawara is the independent medical advisor for this study and has received consultancy fees from Novartis Pharma K.K.

Compliance with ethics guidelines. The study protocol was reviewed and approved by the Independent Ethics Committee/Institutional Review Board at each center. All procedures followed were in accordance with the ethical standards of the responsible committee on human experimentation (institutional and national), the Helsinki Declaration of 1975 , as revised in 2000 and 2008 and Good Clinical Practice guidelines. Informed consent was obtained from all patients for being included in the study.

Open Access. This article is distributed under the terms of the Creative Commons Attribution Noncommercial License which permits any noncommercial use, distribution, and reproduction in any medium, provided the original author(s) and the source are credited.

\section{LIST OF INVESTIGATORS/ INSTITUTIONS}

Akira Numata (Ikebukuro Metropolitan Clinic), Hideki Hanashi (New Medical Research System 
Clinic), Otoya Miho (Miho Clinic), Munechika Noguchi (Shinagawa East One Medical Clinic), Hideki Kaizuka (Pedi Shiodome Clinic), Nobuki Wakao (KASAI Diabetes Clinic), Takashi Lizuka (Asahi Medical Clinic), Tatsuhiro Shimoyama (Shimamura Kinen Hospital), Hiroshi Shimomura (Musashino Polyclinic), Masafumi Sugawara (Dyna Medical Nezu Clinic), Shizuo Kajiyama (Medical Corporation Keisei-kai Kajiyama Clinic), Seiichi Tanaka (Kyushu Rosai Hospital), Yasuhiro Sako (Saiseikai Fukuoka General Hospital), Kiyohide Nunoi (St. Mary's Hospital), Yasuhiro Ono (Takagi Hospital), Makoto Kunisaki (Kunisaki Makoto Clinic), Shizuka Kaneko (Takatsuki Red Cross Hospital), Ryuji Suzuki (Kawasaki Suzuki Medical Clinic), Tomio Inoue (Ageo Central General Hospital) and Kentaro Doi (Rakuwakai Otowa Hospital).

\section{REFERENCES}

1. International Diabetes Federation. IDF Diabetes Atlas. 5th ed. Brussels, Belgium: International Diabetes Federation; 2011. http://www.idf.org/ diabetesatlas/5e/diabetes. Accessed Aug 5, 2013.

2. Kawamori R. Diabetes trends in Japan. Diabetes Metab Res Rev. 2002;18:S9-13.

3. Neville SE, Boye KS, Montgomery WS, Iwamoto K, Okamura M, Hayes RP. Diabetes in Japan: a review of disease burden and approaches to treatment. Diabetes Metab Res Rev. 2009;25:705-16.

4. Fukushima M, Usami $M$, Ikeda $M$, et al. Insulin secretion and insulin sensitivity at different stages of glucose tolerance: a cross-sectional study of Japanese type 2 diabetes. Metabolism. 2004;53:831-5.

5. Japan Diabetes Clinical Data Management Study Group. HbA1c (NGSP) in 2008. Ibaraki. http:// jddm.jp/data/index.html. Accessed Aug 10, 2013.

6. Japan Diabetes Society, Treatment Guide for Diabetes edited by Japan Diabetes Society 2012-2013. Bunkodo Co. Ltd.; 2013.

7. Kirpichnikov D, McFarlane SI, Sowers JR. Metformin: an update. Ann Intern Med. 2002;137:25-33.
8. Ahrén B, Foley JE, Bosi E. Clinical evidence and mechanistic basis for vildagliptin's action when added to metformin. Diabetes Obes Metab. 2011;13:193-203.

9. Ahrén B, Schweizer A, Dejager S, Villhauer EB, Dunning BE, Foley JE. Mechanisms of action of the dipeptidyl peptidase-4 inhibitor vildagliptin in humans. Diabetes Obes Metab. 2011;13:775-83.

10. Pi-Sunyer FX, Schweizer A, Mills D, Dejager S. Efficacy and tolerability of vildagliptin monotherapy in drug-naïve patients with type 2 diabetes. Diabetes Res Clin Pract. 2007;76:132-8.

11. Bosi E, Camisasca RP, Collober C, Rochotte E, Garber AJ. Effects of vildagliptin on glucose control over 24 weeks in patients with type 2 diabetes inadequately controlled with metformin. Diabetes Care. 2007;30:890-5.

12. Garber AJ, Foley JE, Banerji MA, et al. Effects of vildagliptin on glucose control in patients with type 2 diabetes inadequately controlled with a sulphonylurea. Diabetes Obes Metab. 2008;10:1047-56.

13. Garber AJ, Schweizer A, Baron MA, Rochotte E, Dejager S. Vildagliptin in combination with pioglitazone improves glycaemic control in patients with type 2 diabetes failing thiazolidinedione monotherapy: a randomized, placebo-controlled study. Diabetes Obes Metab. 2007;9:166-74.

14. Kothny W, Foley JE, Kozlovski P, Shao Q, Gallwitz $\mathrm{B}$, Lukashevich V. Improved glycaemic control with vildagliptin added to insulin, with or without metformin, in patients with type 2 diabetes mellitus. Diabetes Obes Metab. 2013;15:252-7.

15. Kikuchi M, Abe N, Kato M, Terao S, Mimori N, Tachibana H. Vildagliptin dose-dependently improves glycemic control in Japanese patients with type 2 diabetes mellitus. Diabetes Res Clin Pract. 2009;83:233-40.

16. Iwamoto Y, Kashiwagi A, Yamada N, et al. Efficacy and safety of vildagliptin and voglibose in Japanese patients with Type 2 diabetes: a 12-week, randomized, double-blind, active-controlled study. Diabetes Obes Metab. 2010;12:700-8.

17. Bosi E, Dotta F, Jia Y, Goodman M. Vildagliptin plus metformin combination therapy provides superior glycaemic control to individual monotherapy in treatment-naive patients with type 2 diabetes mellitus. Diabetes Obes Metab. 2009;11:506-15.

18. Kadowaki T, Tajima N, Odawara M, Nishii M, Taniguchi T, Ferreira JCA. Addition of sitagliptin to ongoing metformin monotherapy improves 
glycemic control in Japanese patients with type 2 diabetes over 52 weeks. J Diabetes Investig. 2013;4:174-81.

19. Seino Y, Miyata Y, Hiroi S, Hirayama M, Kaku K. Efficacy and safety of alogliptin added to metformin in Japanese patients with type 2 diabetes: a randomized, double-blind, placebo-controlled trial with an open-label, long-term extension study. Diabetes Obes Metab. 2012;14:927-36.

20. Inagaki $\mathrm{N}$, Watada $\mathrm{H}$, Murai $\mathrm{M}$, et al. Linagliptin provides effective, well-tolerated add-on therapy to pre-existing oral antidiabetic therapy over 1 year in Japanese patients with type 2 diabetes. Diabetes Obes Metab. 2013;15:833-43.

21. Balas B, Baig MR, Watson C, et al. The dipeptidyl peptidase IV inhibitor vildagliptin suppresses endogenous glucose production and enhances islet function after single-dose administration in type 2 diabetic patients. J Clin Endocrinol Metab. 2007;92:1249-55.

22. Odawara M, Suzuki M, Hamada I, Iguchi A. Clinical evaluations of the vildagliptin combination therapy in type 2 diabetes patients - A long term safety study of 52 weeks treatment with vildagliptin as add-on therapy with metformin, TZD, $\alpha$-GI or Glinides. J New Rem Clin. 2012;12:2593-611 (article in Japanese).

23. Matthews DR, Dejager S, Ahrén B, et al. Vildagliptin add-on to metformin produces similar efficacy and reduced hypoglycaemic risk compared with glimepiride, with no weight gain: results from a 2-year study. Diabetes Obes Metab. 2010;12:780-9.

24. Schweizer A, Dejager S, Foley JE, Kothny W. Assessing the general safety and tolerability of vildagliptin: value of pooled analyses from a large safety database versus evaluation of individual studies. Vasc Health Risk Manag. 2011;7:49-57.

25. Foley JE, Jordan J. Weight neutrality with the DPP-4 inhibitor, vildagliptin: mechanistic basis and clinical experience. Vasc Health Risk Manag. 2010;6:541-8.

26. Migoya EM, Bergeron R, Miller JL, et al. Dipeptidyl peptidase- 4 inhibitors administered in combination with metformin result in an additive increase in the plasma concentration of active GLP-1. Clin Pharmacol Ther. 2007;88:801-8. 